\title{
Worldwide Practice in Gastric Cancer Surgery: A 6-Year Update
}

\author{
Emma C. Gertsen ${ }^{a}$ Hylke J.F. Brenkman ${ }^{a, b}$ Leonie Haverkamp ${ }^{c}$ \\ Matthew Read ${ }^{d}$ Jelle P. Ruurda ${ }^{a}$ Richard van Hillegersberg ${ }^{a}$ \\ aDepartment of Surgery, University Medical Center Utrecht, Utrecht University, Utrecht, The Netherlands; \\ bepartment of Surgery, Meander Medical Center, Amersfoort, The Netherlands; 'Department of Surgery, \\ Noordwest Ziekenhuisgroep, Alkmaar, The Netherlands; ${ }^{d}$ Department of Surgery, St Vincent's Hospital Melbourne, \\ Melbourne, VIC, Australia
}

\section{Keywords}

Gastric cancer · Gastrectomy · Laparoscopic gastrectomy ·

Open surgery

\begin{abstract}
Objectives: The aim of the study was to evaluate the current status of gastric cancer surgery worldwide and update the changes compared to a previous survey in 2014. Methods: A cross-sectional survey was sent to surgical members of the International Gastric Cancer Association, pilot centers of the World Organization for Specialized Studies on Diseases of the Esophagus, and the Australian and New Zealand Gastric and Oesophageal Surgeons Association in addition to participants of the 2019 International Gastric Cancer and European Society for Diseases of the Esophagus congresses. Topics addressed included hospital volume, staging, perioperative treatment, surgical approach, anastomotic techniques, lymphadenectomy, and palliative management. Results: Between June 2019 and January 2020, 165 respondents from 44 countries completed the survey. In total, $80 \%$ worked in a hospital performing $>20$ gastrectomies annually. Staging laparoscopy and 18F-fluorodeoxyglucose positron emission tomography with computed tomography were preferred by 68 and 26\% for advanced cancer, and 90\% offered perioperative chemo(radio)therapy to patients. For early cancer, a minimally invasive surgical approach was preferred by $65 \%$
\end{abstract}

C 2021 The Author(s)

Published by S. Karger AG, Basel

This is an Open Access article licensed under the Creative Commons Attribution-NonCommercial-4.0 International License (CC BY-NC) (http://www.karger.com/Services/OpenAccessLicense), applicable to the online version of the article only. Usage and distribution for commercial purposes requires written permission. for distal and by $50 \%$ for total gastrectomy. For advanced cancer, this was preferred by $39 \%$ for distal and by $33 \%$ for total gastrectomy. And $84 \%$ favored a stapled anastomosis, and $14 \%$ created a jejunal pouch as reconstruction during total gastrectomy. A D2 lymphadenectomy was preferred for distal as well as for total gastrectomy, in both early (62 and $71 \%$ ) and advanced (84 and $89 \%$ ) cancer. Conclusion: This international survey demonstrates that perioperative chemotherapy and a D2 lymphadenectomy have now become the preferred treatment for gastric cancer. A minimally invasive surgical approach has gained popularity.

(C) 2021 The Author(s) Published by S. Karger AG, Basel

\section{Introduction}

In 2018, over a million patients were diagnosed with gastric cancer, and it was the third leading cause for cancer-related death, accounting for 782.685 deaths [1]. Several aspects of the diagnostic workup and treatment for gastric cancer are under debate. For example, national guidelines differ in performing $18 \mathrm{~F}$-fluorodeoxyglucose positron emission tomography with computed tomography (FDG-PET/CT), staging laparoscopy, and the use of perioperative treatment [2-4]. In addition, there is an ongoing debate on the value of minimally invasive surgery which was demonstrated to be associated with less post-
Correspondence to:

Emma C. Gertsen, e.c.gertsen@ umcutrecht.nl

Richard van Hillegersberg, r.vanhillegersberg@umcutrecht.nl 


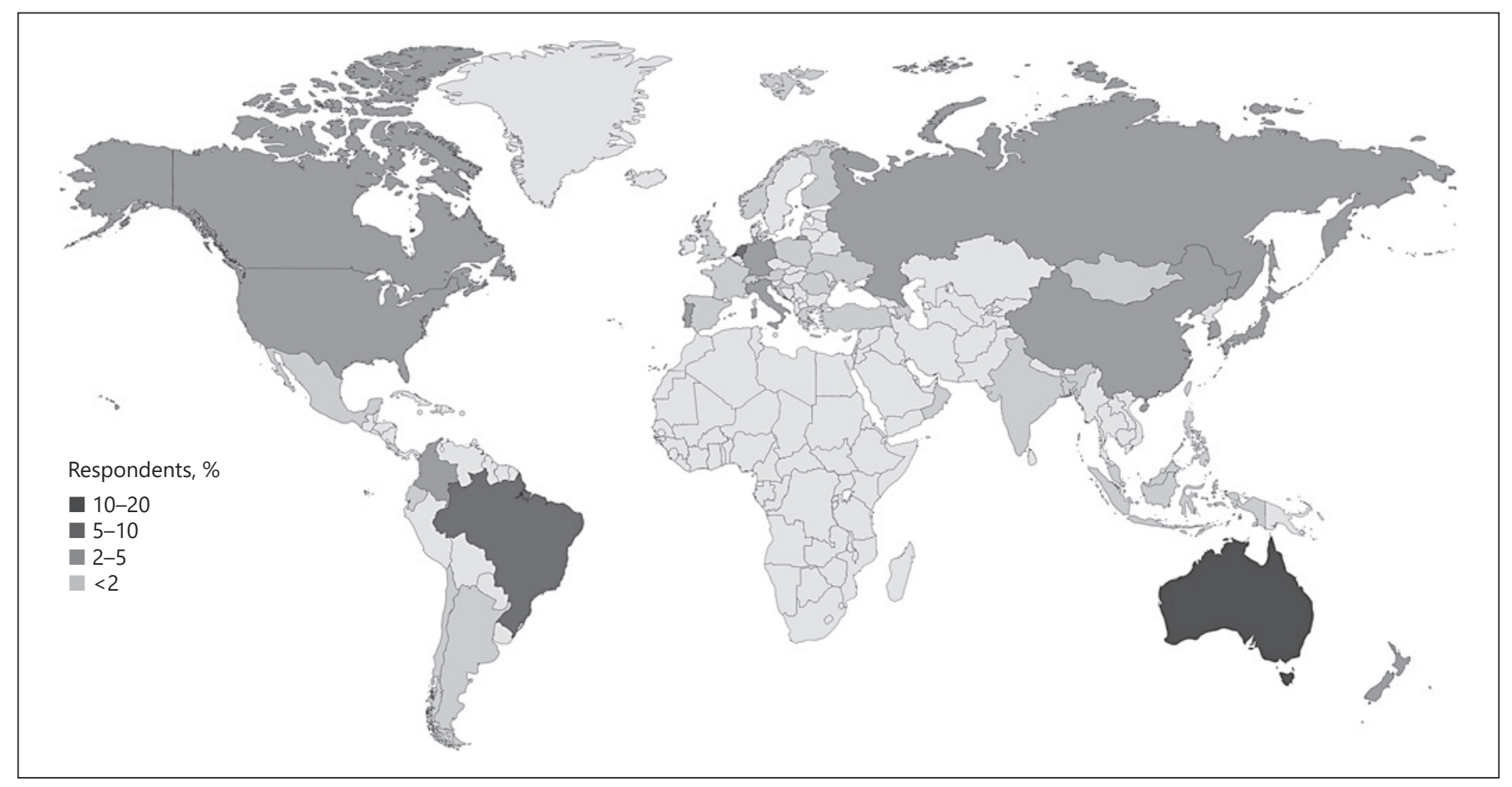

Fig. 1. Number of respondents per participating country.

operative morbidity, faster recovery, and less pain, without impairing long-term outcomes [5-8]. Nevertheless, open surgery remains the treatment of choice for many surgeons [9].

In 2014, our study group conducted an international cross-sectional survey on the surgical treatment of gastric cancer [9]. The aim of the current study was to perform an update of our previous survey in order to identify any trends and regional differences that may exist in the surgical management of gastric cancer. Compared to the previous survey, additional information was also sought regarding preoperative staging and the palliative management of gastric cancer.

\section{Materials and Methods}

All surgical members of the International Gastric Cancer Association(IGCA) and the Australian and New Zealand Gastric and Oesophageal Surgeons Association (ANZGOSA) as well as the heads of the pilot centers involved in the World Organization for Specialized Studies on Diseases of the Esophagus (OESO)-Stanford Platform were sent an electronic invitation for this international cross-sectional survey. In addition, surgical attendees of the 2019 International Gastric Cancer Congress in Prague and the European Society for Diseases of the Esophagus congress in Athens were also invited to participate, through a QR-code that was made

Worldwide Gastric Cancer Surgery available during the conference which provided a direct link to the online survey. The survey has been included in online suppl. File 1 (see www.karger.com/doi/10.1159/000515768 for all online suppl. material). The topics that were assessed included hospital volume, preoperative staging, perioperative chemotherapy, surgical approach, extent of resection, anastomotic and reconstructive techniques, and palliative management. The survey was conducted over an 8-month period from June 2019 to January 2020. Current data were then compared to the data from a previous study conducted by our group in 2014 [9]. Statistical analyses were performed using SPSS version 25.0 (IBM Corp., Armonk, NY, USA), and the $\chi^{2}$ test was used to make comparisons between continents. A $p$ value $<0.05$ was considered statistically significant.

\section{Results}

\section{Demographics}

The survey was sent to all IGCA $(n=910)$ and ANZGOSA $(n=220)$ members, as well as to the heads of OESO pilot centers $(n=21)$. In total, the survey was sent to 1,151 surgeons, of which 179 completed the survey (16\%). Duplicate respondents $(n=14)$ were subsequently excluded, resulting in a specific response rate of $14 \%$. Figure 1 shows the origins of the respondents and their relative contribution to the survey. Of the total 165 respondents originating from 44 different countries, $2 \%$ repre- 
Fig. 2. Annual number of gastrectomies per

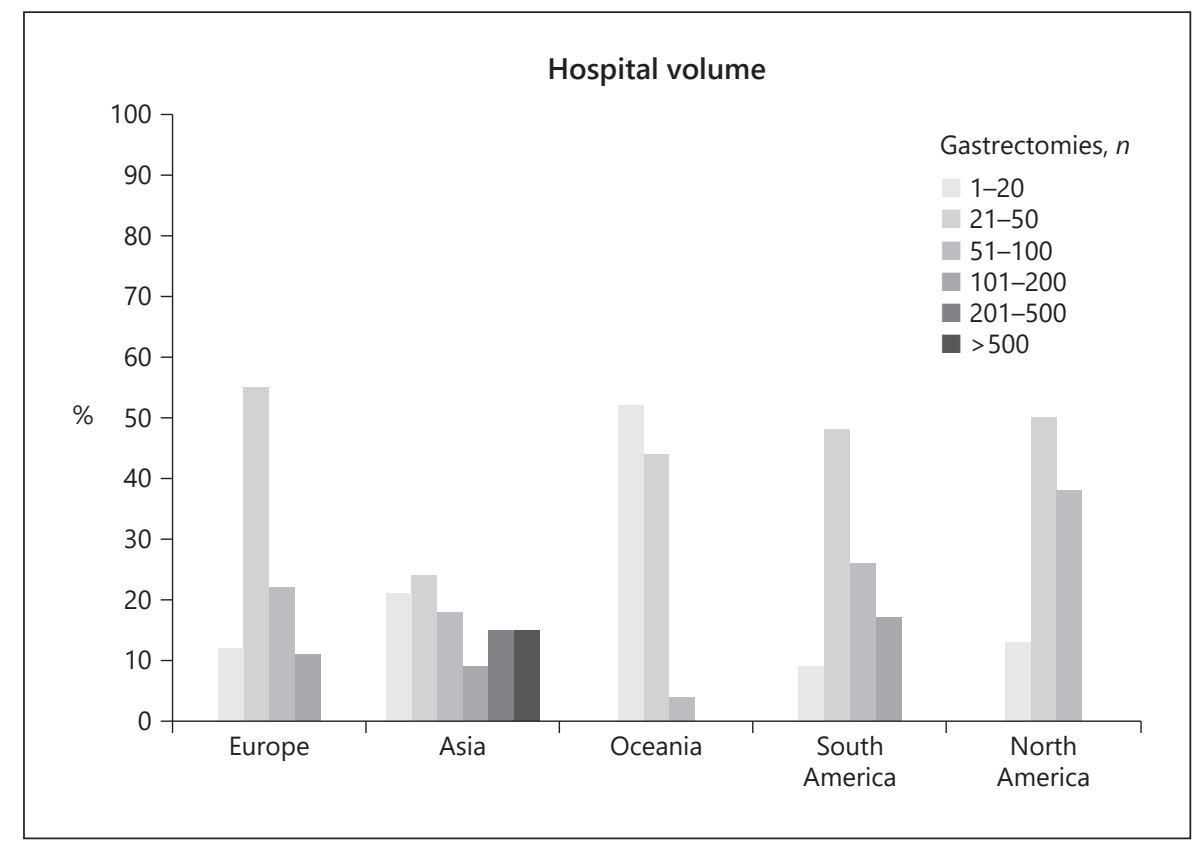
hospital.

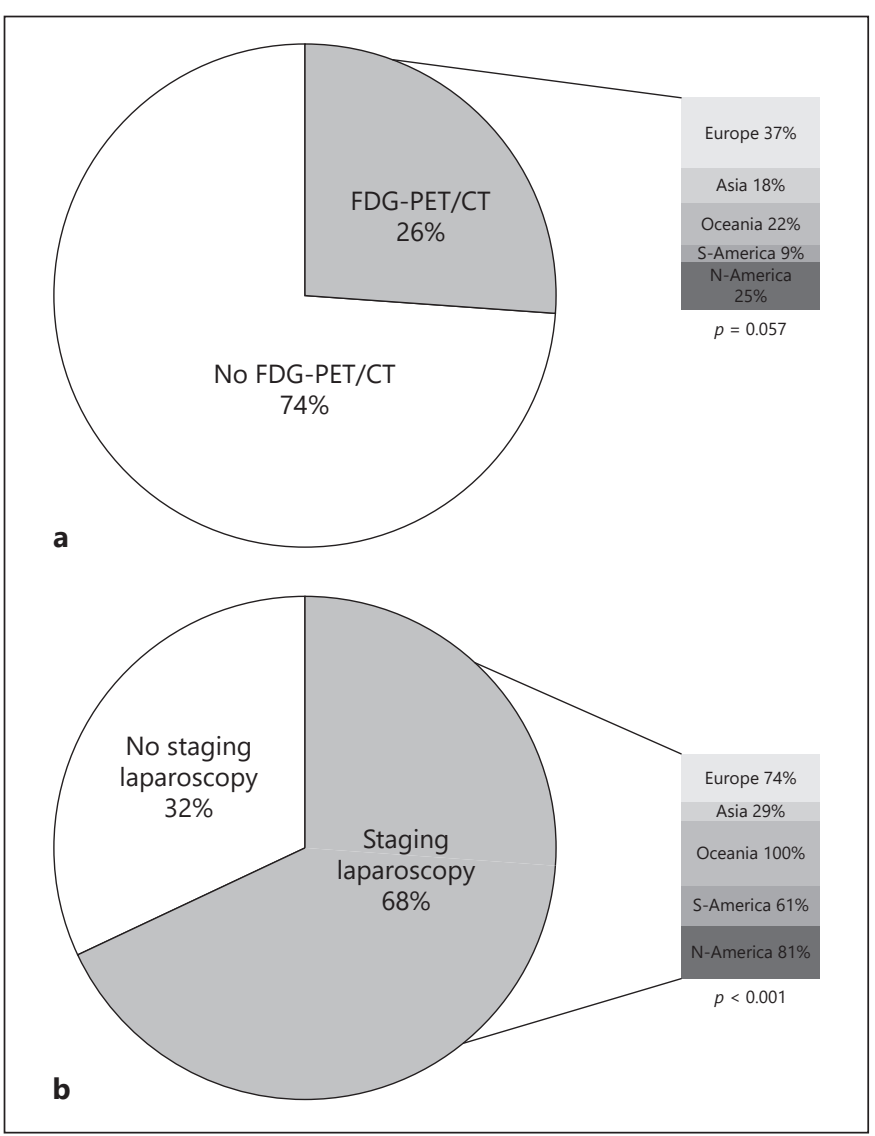

Fig. 3. Global usage of FDG-PET/CT and SL in advanced gastric cancer and percentages per continent. FDG-PET/CT, 18F-fluorodeoxyglucose positron emission tomography with computed tomography. sented low-income countries, $32 \%$ middle-income countries, and $67 \%$ high-income countries. The distribution of respondents by continent was as follows: 65 (39\%) originated from Europe, 34 (21\%) from Asia, 27 (16\%) from Oceania, 23 (14\%) from South America, and 16 (10\%) from North America.

\section{Volume}

Most of the respondents (46\%) worked in hospitals performing 21-50 gastrectomies per year, whereas $20 \%$ worked in hospitals performing $\leq 20$ yearly and $35 \%$ in hospitals performing $>50$ gastrectomies per year. Figure 2 presents the distribution of hospital volumes per continent. The majority of the respondents (67\%) worked in a university hospital.

\section{Staging}

The majority of the respondents routinely performed a staging laparoscopy (68\%) for advanced gastric cancer, whereas only a minority (26\%) routinely performed an FDG-PET/CT. Figure 3 presents the variations in the use of both modalities per continent. Compared to regional hospitals, staging laparoscopy was more frequently performed in university hospitals ( 73 vs. $56 \%, p=0.018$ ).

\section{Perioperative Treatment}

Perioperative chemotherapy, defined as pre- and postoperative chemotherapies with epirubicin, cisplatin, and infused fluorouracil according to the MAGIC trial regi- 
Table 1. Preferred types of perioperative treatment

\begin{tabular}{lrrrrr}
\hline & Europe & Asia & Oceania & $\begin{array}{l}\text { South } \\
\text { America }\end{array}$ & $\begin{array}{l}\text { North } \\
\text { America }\end{array}$ \\
\hline Chemotherapy & $89 \%$ & $67 \%$ & $100 \%$ & $65 \%$ & $94 \%$ \\
Chemoradiotherapy & $3 \%$ & $6 \%$ & $0 \%$ & $22 \%$ & $6 \%$ \\
None & $8 \%$ & $27 \%$ & $0 \%$ & $13 \%$ & $0 \%$ \\
None & $8 \%$ & $27 \%$ & $0 \%$ & $13 \%$ & $0 \%$ \\
\hline
\end{tabular}

Percentages may not add up to 100 , due to rounding. men [10], or a similar protocol, was favored by $84 \%$ of surgeons. Of the remainder, $6 \%$ preferred chemoradiotherapy, while $10 \%$ preferred no perioperative treatment. This was found to differ significantly between continents $(p<0.001)$. In Western countries, the majority used perioperative treatment, whereas in Asia, 27\% preferred no perioperative treatment (see Table 1).

\section{Surgical Approach}

When performing a distal gastrectomy for early gastric cancer, $64 \%$ of the surgeons preferred a minimally invasive approach. However, for locally advanced gastric cancer, only $39 \%$ of respondents preferred a minimally invasive approach. When performing a total gastrectomy, $50 \%$ of the surgeons performed a minimally invasive approach for early gastric cancer and only $33 \%$ performed a minimally invasive approach in the setting of advanced cancer. Some minor differences were seen across continents (Fig. 4).

\section{Extent of Dissection}

A D2 resection was favored by $62 \%$ of respondents for distal and by $71 \%$ for total gastrectomies performed for early cancers. For advanced cancers, this increased to $84 \%$ for a distal gastrectomy and $89 \%$ for a total gastrectomy. For early cancers, a D2 resection was favored most frequently by respondents from South America and Europe (Table 2). Few surgeons from Europe and Asia performed a D3 lymphadenectomy. The majority of surgeons also favored to resect the greater omentum in the setting of advanced cancer (89\%).

\section{Anastomoses}

The majority of the respondents preferred a mechanical circular stapler when constructing the esophago-jejunal anastomosis after total gastrectomy (61\%), compared to $23 \%$ who preferred a mechanical linear stapler and $16 \%$ a hand-sewn anastomosis, which differed between continents $(p=0.016$, Table 3$)$. The results of the survey re- vealed that $86 \%$ of surgeons favored a direct reconstruction, whereas merely $14 \%$ favored a jejunal pouch for reconstruction following total gastrectomy.

\section{Metastatic Disease}

In the case of peritoneal metastases, $26 \%$ of respondents would offer hyperthermic intraperitoneal chemotherapy (HIPEC) and cytoreductive surgery provided the Peritoneal Cancer Index (PCI) was $\leq 6$. For a PCI of 7-12, only $9 \%$ of respondents would offer such treatment. In Europe, HIPEC is considered most often: $45 \%$ versus $4-25 \%$ in other continents, $p<0.001$. In the case of distant metastases, $87 \%$ of respondents would perform a palliative gastrectomy in selected cases, which did not differ between continents.

\section{Comparison to the 2014 Survey}

Table 4 shows the data of the present study in comparison to the data from the survey conducted in 2014. The percentage of high-volume centers, which is defined as a volume of $\geq 20$ gastrectomies yearly, remained the same. The use of perioperative chemotherapy increased to $84 \%$, whereas the use of chemoradiotherapy decreased. Moreover, the use of minimally invasive surgery for advanced cancers increased, with a more than 4-fold increase for distal gastrectomy ( 9 vs. $39 \%$ ) and a 5.5-fold increase for total gastrectomy (6 vs. 33\%). Regarding the anastomotic technique, the percentage of surgeons favoring a hand-sewn anastomosis doubled (8-16\%). Last, an increase in D2 lymphadenectomy for early cancers was observed.

\section{Discussion}

This study evaluated current worldwide trends in surgical treatment for gastric cancer, by conducting a survey which was sent to upper gastrointestinal surgeons globally. The results show that the majority of surgeons 


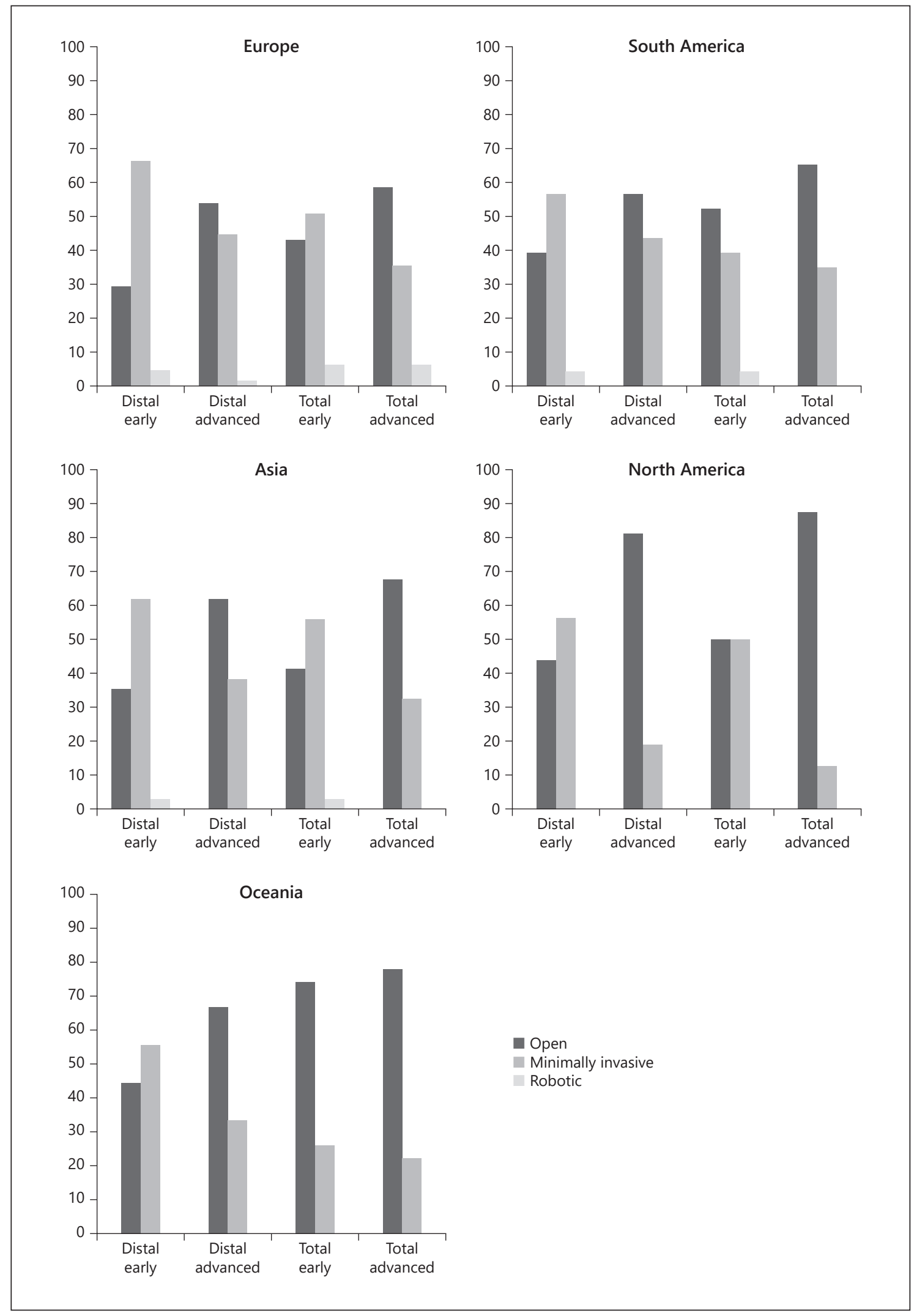

Fig. 4. Surgical approach across continents for early and advanced gastric cancer. 
Table 2. Percentage of at least a D2 lymphadenectomy, divided per tumor stage and type of procedure

\begin{tabular}{lllllr}
\hline & $\begin{array}{l}\text { Europe, } \\
\%\end{array}$ & $\begin{array}{l}\text { Asia, } \\
\%\end{array}$ & $\begin{array}{l}\text { Oceania, } \\
\%\end{array}$ & $\begin{array}{l}\text { South America, } \\
\%\end{array}$ & $\begin{array}{l}\text { North America, } \\
\%\end{array}$ \\
\hline Distal gastrectomy for early cancer & 71 & 53 & 52 & 74 & 50 \\
Distal gastrectomy for advanced cancer & $89^{*}$ & 94 & 67 & 87 & 94 \\
Total gastrectomy for early cancer & $85^{* *}$ & 62 & 48 & 87 & 53 \\
Total gastrectomy for advanced cancer & $94^{* * *}$ & $97^{* * * *}$ & 74 & 87 & 0.008 \\
\hline
\end{tabular}

* Including 8\% D3 resections. ${ }^{* *}$ Including 3\% D3 resections. ${ }^{* * *}$ Including 5\% D3 resections. ${ }^{* * *}$ Including 3\% D3 resections.

Table 3. Type of anastomosis

\begin{tabular}{llllll}
\hline & $\begin{array}{l}\text { Europe, } \\
\%\end{array}$ & $\begin{array}{l}\text { Asia, } \\
\%\end{array}$ & $\begin{array}{l}\text { Oceania, } \\
\%\end{array}$ & $\begin{array}{l}\text { South America, } \\
\%\end{array}$ & $\begin{array}{l}\text { North America, } \\
\%\end{array}$ \\
\hline Hand-sewn & 15 & 3 & 30 & 4 & 38 \\
Mechanical, circular stapler & 63 & 65 & 59 & 61 & 44 \\
Mechanical, linear stapler & 22 & 32 & 11 & 35 & 22 \\
\hline
\end{tabular}

Percentages may not add up to 100 , due to rounding.

Table 4. Comparison of the current data with those of the previous survey

\begin{tabular}{lcc}
\hline & 2014 & 2020 \\
\hline No. respondents & 227 & 165 \\
High-volume centers & $79 \%$ & $80 \%$ \\
Perioperative therapy, \% & & 84 \\
$\quad$ Chemotherapy & 73 & 6 \\
Chemoradiotherapy & 12 & 10 \\
None & 16 & $64^{\times}$ \\
Surgical approach, \% minimally invasive & & $39^{\times \times}$ \\
Distal gastrectomy for early cancer & 65 & $50^{\times \times \times}$ \\
Distal gastrectomy for advanced cancer & 9 & $33^{\times \times \times \times}$ \\
Total gastrectomy for early cancer & 49 & 84 \\
Total gastrectomy for advanced cancer & 6 & 16 \\
Anastomosis, \% & & 14 \\
Mechanical stapler & 92 & 62 \\
Hand-sewn & 8 & $84^{*}$ \\
Jejunal pouch & 17 & $71^{* *}$ \\
Extent of dissection, \% & & $89^{* * *}$ \\
D2 in distal gastrectomy for early cancer & 42 & 89 \\
D2 in distal gastrectomy for advanced cancer & 92 & 165 \\
D2 in total gastrectomy for early cancer & 41 & 93 \\
D2 in total gastrectomy for advanced cancer & 89 & 227 \\
Greater omentum & & \\
No. of respondents & & \\
\hline
\end{tabular}

${ }^{\times}$Including $3 \%$ robot-assisted. ${ }^{\times \times}$Including $1 \%$ robot-assisted. ${ }^{\times \times \times}$Including $4 \%$ robot-assisted. ${ }^{x \times \times \times}$ Including $2 \%$ robot-assisted. ${ }^{*}$ Not accounting $3 \%$ D3 resections. ${ }^{* *}$ Not accounting $1 \%$ D3 resections. ${ }^{* * *}$ Not accounting $2 \%$ D3 resections. 
worked in a high-volume hospital (81\%) and offered patients perioperative chemo(radio)therapy (90\%). For early gastric cancer, a minimally invasive approach is favored by the majority (50-64\%), whereas in the case of advanced cancer, a minimally invasive approach was favored by only $33-39 \%$. Regarding preoperative staging, anastomotic technique, extent of dissection, and treatment in the setting of metastatic disease, some differences between continents were identified.

Regarding the use of FDG-PET/CT in advanced gastric cancer, no differences across continents were found. However, staging laparoscopy was found to be performed much less frequently in Asian countries than Western countries. This is most likely reflective of the differences in guideline recommendations between countries. However, it may also be influenced by the fact that patients from Western countries typically present with more advanced tumors and therefore tend to have a higher chance of having peritoneal metastases $[4,11,12]$.

In line with the previous survey [9], respondents from Europe favored perioperative chemotherapy more often than in Asia. These findings correspond to the recommendations from regional guidelines which have remained relatively consistent across the study period. In Europe, perioperative chemotherapy remains the standard of care. Conversely, in Asia, surgery is performed up front, followed by adjuvant chemotherapy for advanced cancers [6]. Interestingly, the use of perioperative chemotherapy even appears to have increased in Europe. This increase is most likely related to the encouraging results from the FLOT-4 trial, which revealed an improved survival for patients receiving fluorouracil plus leucovorin, oxaliplatin, and docetaxel (FLOT)) compared with epirubicin and cisplatin plus either fluorouracil or capecitabine (ECF/ECX) [13]. To date, no solid data are available to support the use of neoadjuvant chemoradiotherapy as a standard of care, and this may explain the decrease in use when compared to the previous survey. Although some studies reported on possible benefits of (adding) neoadjuvant chemoradiotherapy, such as improved pathological complete response and R0 rates [14], results of randomized controlled trials are to be awaited $[15,16]$.

When comparing the current results with the survey of 2014, it was found that surgeons favor a minimally invasive approach more often, especially in Europe where a gradual change from open to minimally invasive gastrectomy was observed in early cancers. This is probably explained by an increasing amount of the literature on the benefits of minimally invasive surgery. In this context, several Asian randomized controlled trials researched these topics and reported that laparoscopic gastrectomy is safe for early cancers $[5,8,17]$, and may result in less postoperative morbidity and faster recovery after distal gastrectomy for advanced cancer [6, 7]. In this enumeration, level 1 evidence reporting on laparoscopic total gastrectomy for advanced cancer is lacking. However, a Dutch multicenter randomized controlled trial (LOGICA trial [NCT02248519]) recently reported laparoscopic total gastrectomy for patients with predominantly advanced cancer to be safe and feasible [18]. In addition, no differences regarding postoperative morbidity, short-term oncological outcomes, and quality of life were reported, although laparoscopic gastrectomy was associated with less blood loss.

Over the past 6 years, the percentage of surgeons using a jejunal pouch remained relatively constant, whereas the percentage of surgeons creating a hand-sewn anastomosis doubled to $16 \%$. Nevertheless, mechanical staplers remained the favored approach reported by the majority of respondents. It was previously described that stapling methods embrace benefits such as shorter operating time, shortened hospitalization, faster functional postoperative recovery, and reduced anastomotic leakage [19]. Despite these possible benefits of mechanical staplers, there are no clear international guidelines regarding this topic.

Whereas the results of the previous survey showed that a D1+ lymphadenectomy was preferred by most of the surgeons in the case of early cancer, the current results reveal that the majority performs at least a D2 lymphadenectomy in both early and advanced cancer. This is in line with current Western guidelines recommending a D2 lymphadenectomy routinely, and although not yet recommended by eastern guidelines, a meta-analysis, including also Asian trials, reported that D2 lymphadenectomy with spleen and pancreas preservation increases long-term survival $[4,20]$.

Another topic that is not yet established in most national guidelines is the treatment with cytoreductive surgery and HIPEC for patients with positive cytology and/ or peritoneal metastases. The first studies investigating this originated from Asia and reported a possible survival gain after 1 and 3 years in patients with limited peritoneal disease $[21,22]$. Due to significant differences between eastern and Western populations [12], similar trials have been established in the West. These include the European GASTRIPEC trial, which is assessing the added effect of cytoreductive surgery alone or in combination with HIPEC, and the PERISCOPE-II trial, which is evaluating the role of gastrectomy in combination with both cytoreductive surgery and HIPEC versus palliative man- 
agement alone $[23,24]$. The fact that both of these studies are being conducted in Europe may provide a possible explanation for the uptake of cytoreductive surgery and HIPEC across European respondents. Based on results from these studies, indicating that HIPEC can be performed safely and may even prevent peritoneal recurrence and prolong survival, there may also be a future role for prophylactic HIPEC [25]. In the case of distant metastases, a controversial topic that is currently under debate, $87 \%$ of surgeons indicated that they would perform a palliative resection in selected cases, for example, in the case of fit, symptomatic patients. Although the Asian REGATTA-trial demonstrated no survival benefit, several cohort studies suggest the opposite [26-28]. For now, the results of the Dutch COSTA and the German RENAISSANCE trial, both evaluating potential benefits of palliative gastrectomy, should be awaited [29].

One of the key limitations of this study is that statistical analyses comparing the current results with those of the previous survey could not be performed. This is due to a low number of respondents and methodological differences in how the surveys were conducted. This resulted in different cohorts of respondents between the surveys with different geographical distributions. In addition, when assessing the response rate, no rate for QR-code respondents could be determined, and it was assumed that respondents were members of solely one association. This resulted in a relatively low response rate, which is probably an underestimation. Due to the low number of respondents from low-income countries, it was decided not to perform an analysis evaluating this subdivision, although it would have been interesting to learn how underrepresented regions manage gastric cancer. Nonetheless, due to its international design, we believe the results to be a representative of expert surgeons' opinions, as the majority of the respondents worked in a high-volume hospital (defined as $\geq 20$ gastrectomies annually according to the literature), providing both a useful and current update on the varying expert opinions and practices that exist around the world.

\section{Conclusion}

This 6-year update of the previous survey from 2014 reflects worldwide trends in gastric cancer surgery and reveals that surgeons favor a minimally invasive approach more often, especially for early cancers, combined with a D2 lymph node dissection, and that respondents are increasingly adopting perioperative therapy.

\section{Acknowledgements}

The authors would like to thank the International Gastric Cancer Association (IGCA), expert members of the pilot centers involved in the World Organization for Specialized Studies on Diseases of the Esophagus (OESO)-Stanford Platform, and the Australian and New Zealand Gastric and Oesophageal Surgeons Association (ANZGOSA) for sending out the invitations. The authors greatly appreciate the cooperation of the individual respondents. M.R. is the recipient of the senior lecturer fellowship from the Royal Australasian College of Surgeons.

\section{Statement of Ethics}

The paper is exempt from ethical committee approval according to Dutch law as it was a cross-sectional survey and no patient data were used. Informed consent of participants was not directly obtained but inferred by completion of the questionnaire/participation in the interview.

\section{Conflict of Interest Statement}

The authors have no conflicts of interest to disclose.

\section{Funding Sources}

This study did not receive any funding.

\section{Author Contributions}

E.C.G. contributed substantially to conceptualization, methodology, validation, formal analysis, investigation, resources, writing - original draft, writing - review and editing, visualization, and project administration. H.J.F.B. made substantial contributions to conceptualization, methodology, validation, formal analysis, investigation, resources, writing - original draft, writing - review and editing, visualization, and project administration. L.H. made substantial contributions to conceptualization, methodology, validation, formal analysis, investigation, resources, writing - review and editing, and visualization. M.R. contributed substantially to conceptualization, methodology, validation, formal analysis, investigation, resources, writing - review and editing, and visualization. J.P.R. made substantial contributions to conceptualization, methodology, validation, formal analysis, investigation, resources, writing - original draft, writing - review and editing, visualization, and project administration. R.v.H. contributed substantially to conceptualization, methodology, validation, formal analysis, investigation, resources, writing - original draft, writing - review and editing, visualization, and project administration.

All the authors have approved the submitted versions and have agreed both to be personally accountable for the author's own contributions and to ensure that questions related to the accuracy or integrity of any part of the work, even ones in which the author was not personally involved, are appropriately investigated, resolved, and the resolution documented in the literature. 


\section{References}

1 Bray F, Ferlay J, Soerjomataram I. Global Cancer Statistics 2018: GLOBOCAN estimates of incidence and mortality worldwide for 36 cancers in 185 countries; 2018. p. 394424.

2 Integraal Kankercentrum Nederland. Diagnostiek, behandeling en follow-up van het maagcarcinoom; 2016. p. 1-7. Available from: http://www.oncoline.nl/uploaded/ docs/Maagcarcinoom/Richtlijn maagcarcinoom.pdf.

3 Sano T, Kodera Y. Japanese gastric cancer treatment guidelines 2010 (ver. 3). Gastric Cancer. 2011;14(2):113-23.

4 Waddell T, Verheij M, Allum W, Cunningham D, Cervantes A, Arnold D. Gastric cancer: ESMO-ESSO-ESTRO clinical practice guidelines for diagnosis, treatment and follow-up. Ann Oncol. 2013;24(Suppl 6):vi5763.

5 Kim HH, Han SU, Kim MC, Kim W, Lee HJ, Ryu SW, et al. Effect of laparoscopic distal gastrectomy vs open distal gastrectomy on long-term survival among patients with stage I gastric cancer: the KLASS-01 randomized clinical trial. JAMA Oncol. 2019;5(4):506-13.

6 Lee HJ, Hyung WJ, Yang HK, Han SU, Park YK, An JY, et al. Short-term outcomes of a multicenter randomized controlled trial comparing laparoscopic distal gastrectomy with D2 lymphadenectomy to open distal gastrectomy for locally advanced gastric cancer (KLASS-02-RCT). Ann Surg. 2019;270(6): 983-91.

7 Yu J, Huang C, Sun Y, Su X, Cao H, Hu J, et al. Effect of laparoscopic vs open distal gastrectomy on 3-year disease-free survival in patients with locally advanced gastric cancer: the CLASS-01 randomized clinical trial. J Am Med Assoc. 2019;321:1983-92.

8 Hyung WJ, Yang HK, Han SU, Lee YJ, Park JM, Kim JJ, et al. A feasibility study of laparoscopic total gastrectomy for clinical stage I gastric cancer: a prospective multi-center phase II clinical trial, KLASS 03. Gastric Cancer. 2019;22(1):214-22.

9 Brenkman HJ, Haverkamp L, Ruurda JP, Van Hillegersberg R. Worldwide practice in gastric cancer surgery. World J Gastroenterol. 2016;22(15):4041-8.

10 Cunningham D, Allum WH, Stenning SP, Thompson JN, Van de Velde CJ, Nicolson M, et al. Perioperative chemotherapy versus surgery alone for resectable gastroesophageal cancer. N Engl J Med. 2006;355(1):11-20.

11 Smyth EC, Verheij M, Allum W, Cunningham D, Cervantes A, Arnold D, et al. Gastric cancer: ESMO clinical practice guidelines for diagnosis, treatment and follow-up. Ann Oncol. 2016;27(Suppl 5):v38-49.
12 Griffin SM. Gastric cancer in the East: same disease, different patient. Br J Surg. 2005; 92(9):1055-6

13 Al-Batran SE, Homann N, Pauligk C, Goetze TO, Meiler J, Kasper S, et al. Perioperative chemotherapy with fluorouracil plus leucovorin, oxaliplatin, and docetaxel versus fluorouracil or capecitabine plus cisplatin and epirubicin for locally advanced, resectable gastric or gastro-oesophageal junction adenocarcinoma (FLOT4): a ra. Lancet. 2019;393:194857.

14 Trip AK, Stiekema J, Visser O, Dikken JL, Cats A, Boot $\mathrm{H}$, et al. Recent trends and predictors of multimodality treatment for oesophageal, oesophagogastric junction, and gastric cancer: a Dutch cohort-study. Acta Oncol. 2015;54(10):1754-62.

15 Leong T, Smithers BM, Haustermans K, Michael M, Gebski V, Miller D, et al. TOPGEAR: a randomized, phase III trial of perioperative ECF chemotherapy with or without preoperative chemoradiation for resectable gastric cancer: interim results from an international, intergroup trial of the AGITG, TROG, EORTC and CCTG. Ann Surg Oncol. 2017; 24(8):2252-8

16 Slagter AE, Jansen EPM, van Laarhoven HWM, van Sandick JW, van Grieken NCT, Sikorska K, et al. CRITICS-II: a multicentre randomised phase II trial of neo-adjuvant chemotherapy followed by surgery versus neo-adjuvant chemotherapy and subsequent chemoradiotherapy followed by surgery versus neo-adjuvant chemoradiotherapy followed by surgery in resecta. BMC Cancer. 2018;18(1):877.

17 Katai H, Mizusawa J, Katayama H, Takagi M, Yoshikawa T, Fukagawa T, et al. Short-term surgical outcomes from a phase III study of laparoscopy-assisted versus open distal gastrectomy with nodal dissection for clinical stage IA/IB gastric cancer: Japan Clinical Oncology Group Study JCOG0912. Gastric Cancer. 2017;20(4):699-708.

18 van der Veen A, Brenkman HJF, Seesing MFJ, Haverkamp L, Luyer MDP, Nieuwenhuijzen GAP, et al. Laparoscopic versus open gastrectomy for gastric cancer (LOGICA): a multicenter randomized clinical trial. J Clin Oncol. 2021;39(9):978-89.

19 Liu BW, Liu Y, Liu JR, Feng ZX. Comparison of hand-sewn and stapled anastomoses in surgeries of gastrointestinal tumors based on clinical practice of China. World J Surg Oncol. 2014;12:292-6.

20 Jiang L, Yang KH, Guan QL, Zhao P, Chen Y, Tian JH. Survival and recurrence free benefits with different lymphadenectomy for resectable gastric cancer: a meta-analysis. J Surg Oncol. 2013;107(8):807-14.
21 Desiderio J, Chao J, Melstrom L, Warner S, Tozzi F, Fong Y, et al. The 30-year experienceA meta-analysis of randomised and highquality non-randomised studies of hyperthermic intraperitoneal chemotherapy in the treatment of gastric cancer. Eur J Cancer. 2017;79:1-14.

22 Coccolini F, Cotte E, Glehen O, Lotti M, Poiasina E, Catena F, et al. Intraperitoneal chemotherapy in advanced gastric cancer. Metaanalysis of randomized trials. Eur J Surg Oncol. 2014;40:12-26.

23 Rau B, Loeffler M, Rau H-G, Sulkowski U, Kuhlmann J, Keck AW, et al. Perioperative chemotherapy and cytoreductive surgery with versus without HIPEC in gastric cancer with limited peritoneal metastases: a randomized phase III study (GASTRIPEC). J Clin Oncol. 2017;33(15).

24 Koemans WJ, Van Der Kaaij RT, Boot H, Buffart T, Veenhof AAFA, Hartemink KJ, et al. Cytoreductive surgery and hyperthermic intraperitoneal chemotherapy versus palliative systemic chemotherapy in stomach cancer patients with peritoneal dissemination, the study protocol of a multicentre randomised controlled trial (PERISCOPE II). BMC Cancer. 2019;19(1):1-8.

25 Brenkman HJF, Päeva M, Van Hillegersberg R, Ruurda JP, Mohammad NH. Prophylactic Hyperthermic Intraperitoneal Chemotherapy (HIPEC) for gastric cancer: a systematic review; 2019.

26 Fujitani K, Yang HK, Mizusawa J, Kim YW, Terashima M, Han SU, et al. Gastrectomy plus chemotherapy versus chemotherapy alone for advanced gastric cancer with a single non-curable factor (REGATTA): a phase 3, randomised controlled trial. Lancet Oncol. 2016;17(3):309-18.

27 Hartgrink HH, Putter H, Klein Kranenbarg E, Bonenkamp JJ, van de Velde CJ. Value of palliative resection in gastric cancer. Br J Surg. 2002;89(11):1438-43.

28 Bonenkamp JJ, Sasako M, Hermans J, van de Velde CJ. Tumor load and surgical palliation in gastric cancer. Hepatogastroenterology. 2001;48(41):1219-21.

29 Al-Batran SE, Goetze TO, Mueller DW, Vogel A, Winkler M, Lorenzen S, et al. The RENAISSANCE (AIO-FLOT5) trial: Effect of chemotherapy alone vs. chemotherapy followed by surgical resection on survival and quality of life in patients with limited-metastatic adenocarcinoma of the stomach or esophagogastric junction: a phase III tri. BMC Cancer. 2017;17:1-7. 